\title{
Presentism: Foreigner-Friendly or Xenophobic?
}

\author{
Bryan Frances \\ Forthcoming in Australasian Journal of Philosophy
}

Abstract

I argue that for all we know there are perfectly ordinary actual entities that are temporal in the usual sense and yet never present, past, or future. This epistemic fact requires us to modify the theses of presentism and eternalism. More importantly, it generates three new and quite serious objections to presentism, which I formulate and partially evaluate in this paper.

Keywords: presentism; eternalism; modal realism; disconnected times; ontology; philosophy of time

\section{What Presentism and Eternalism are}

Suppose you're blowing soap bubbles for some children. You make a big one and watch it float away. And then it pops. This kind of temporal change-something was temporally present and then was not temporally present-seems ontological.

The temporal change seems ontological in the sense that it marks an adjustment in the "furniture of the world", as philosophers tend to use the latter expression. I don't think we can define 'ontological' any more than we can define 'existence'; most likely it is a structurally primitive notion that doesn't permit illuminating definition. So we can't hope for a revealing definition of 'ontological change'.

But we can say something that may help a little: an ontological change is not like a leaf changing its colour or moving from one place to another, where you have the same things before as after the change. (Set aside the view that the presentist should say that every non-Cambridge change in properties is an ontological change because the relevant tropes go out of or pop into existence.) When the bubble moves from one place to another there is little support for the idea that this change involves a numerical adjustment in the furniture of the world, but when it pops it looks as though there is such an adjustment. When the bubble changed colour, there was no ontological change; when it popped, there was such a change. Just as there seems to be an ontological distinction between an actual and a merely possible bubble, there seems to be an ontological distinction between a present and non-present bubble.

So when something stops or starts being temporally present-that's what I mean by 'temporal change'-it seems that there is an ontological alteration that does not happen when something just moves around spatially or otherwise changes its characteristics. Furthermore, the ontological change works this way: when an object is temporally present it falls under the core ontological notion, and when it's no longer the case that it's temporally present, it's no longer the case that it falls under the core ontological notion. 
Hence, we have the thesis that there is an ontological status $\mathrm{E}$ such that at any given time, temporally present as well as (depending on certain other ontological matters) abstract entities have $E$ but it's not the case that wholly past or wholly future entities have $E$. This is presentism. ${ }^{1}$

The presentist is free to insist that $E$ is not the property of being temporally present, since she might think that abstract entities fall under $E$ at every moment but do not do so in virtue of ever being temporally present. By 'abstract' I mean 'not temporally present at any time'. Philosophers used to say things like 'Numbers exist now but not in the now'; presentists are free to believe in such abstract entities while claiming that past and future entities don't fall under $E$. Indeed, I suspect that most contemporary presentists believe in abstracta.

The non-presentist, or eternalist, will say that the presentist is correct in thinking that temporally present entities have a status that past and future entities lack. ${ }^{2}$ Amazingly enough, we have a term for that status: 'temporally present'. But she will deny that this is an ontological status: she says that there are no temporal changes that are ontological. For the eternalist, temporal presence applies to only present entities (obviously, subject to the possible relativity of 'present'), just as the presentist says, but distinctions in temporal presence don't indicate ontological distinctions any more than distinctions in spatial presence indicate ontological distinctions. Entities that are in New York have a status that entities outside of New York lack, but this doesn't mean that New York entities have an ontological status non-New York entities lack. Similarly, entities that are temporally present have a status that temporal entities that aren't temporally present lack, but according to the eternalist this doesn't mean that temporally present entities have an ontological status non-present temporal entities lack.

Contemporary philosophers of time think of the presentism-eternalism debate in a variety of ways, but I will focus on some claims that are commonly accepted by all parties (setting aside questions of their logical form, since they won't concern us). ${ }^{3}$

\footnotetext{
${ }^{1}$ Wise presentists admit that there is a perfectly good and normal sense of ' $x$ exists' according to which ' $x$ exists' comes out true when evaluated with respect to a time when $\mathrm{x}$ is wholly past. To think otherwise is to misunderstand the resources of English. A similar point holds for 'there are Fs'. Eternalists face the same issue: they know that there is a perfectly good and normal sense of ' $x$ doesn't exist' according to which ' $x$ doesn't exist' comes out true when evaluated with respect to a time when $\mathrm{x}$ is wholly past. Again, that's just the way $21^{\text {st }}$ century English works.
}

In order to set such meanings aside, presentists and eternalists alike have to specify how they are using 'x exists'. They argue, or more often merely assume, that there is some "core" notion of existence that the presentist/non-presentist issue is about. I'm using 'E' to pick out that notion. (I don't need to argue for it, as my arguments merely grant for the sake of argument the existence of E.)

${ }^{2}$ There are several kinds of non-presentism. I will ignore all but eternalism, which holds that there is no ontological distinction among past, present, and future.

${ }^{3}$ For introductions to presentism, see Crisp [2003] and Markosian [2004]; for a treatment of the important issues regarding logical form, see Crisp [2004] and Sider [2006]. 
- Presentism says that the entities that fall under $E$ at a given time are not wholly past or wholly future with respect to that time, whereas eternalism says that all those entities fall under $\mathrm{E}$ at every time.

- Presentism says that the entities that fall under $E$ at a given time are either abstract or are temporally present with respect to that time. Eternalism says that the entities that fall under $E$ at a given time are abstract, temporally present, past, or future.

I think the first bullet point is true but both parts of the second bullet point might be false. More exactly, the presentist should not be confident that at a given time $E$ covers only abstract entities plus entities that are temporally present at that time, and the eternalist should not be confident that at a given time $E$ covers only past, present, future, and abstract entities. Instead, both philosophers should admit that there may well be things that are perfectly ordinary temporal entities and yet are never in our past, present, or future. However, there is a price to be paid for this open-mindedness, as it leads to three new objections to presentism, which I articulate and briefly examine near the end of this paper.

\section{The Case for Taking Temporal Foreigners Seriously}

Does the actual world contain spatiotemporal regions whose occupants bear no spatial or temporal relations to the occupants of our spatiotemporal region? Perhaps there are other actual big bangs not spatiotemporally related to ours that generate such spatiotemporal regions. Call the entities of such regions 'spatiotemporally foreign', or 'temporally foreign' or 'foreign' for short: $\mathrm{x}$ is spatiotemporally foreign to $y$ in a particular possible world $\mathrm{W}=\mathrm{x}$ and $\mathrm{y}$ are temporal entities in $\mathrm{W}$ but in $\mathrm{W}$ they bear no spatial or temporal relations to one another. The entities that are foreign with respect to us need not be exotic in any way: they may be completely ordinary things like planets or flowers made of familiar atoms. A "maximal" spatiotemporal region is a spatiotemporal region that contains all entities that bear any spatial or temporal relations to any entities in that region; it is a "universe", in one sense of that word. An "atemporal" entity is an entity that is not in any spatiotemporal region, and not merely absent from our spatiotemporal region. For instance, although both numbers and foreign flowers are not in our past, present, or future, the numbers but not the flowers are atemporal, given the common assumption regarding the metaphysics of numbers.

A foreigner with respect to us is an entity that is not part of our spatiotemporal manifold and yet is part of some other spatiotemporal manifold. An abstract object such as a number is an entity that is not part of any spatiotemporal manifold whatsoever. The number 7 doesn't "bear any temporal relations" to us in this sense: it is never any spatiotemporal distance from us (as it's not part of our manifold). This holds despite the fact that 7 always exists. M etaphysicians sometimes say, metaphorically, that 7 is "outside" our spatiotemporal universe and yet always exists-the 'always exists' doesn't mean that it is part of our manifold. A foreigner doesn't "bear any temporal relations" to us in the exact same sense: everything I just said about 7 holds for a foreigner. Again, the primary difference between 7 and a foreigner is that only the latter is in some spatiotemporal manifold.

Hence, given a certain view in the philosophy of mathematics, 'The number 7 always exists' is true even though it doesn't "bear temporal relations" to us in the sense just described; similarly, given a certain view in the philosophy of time 'The foreigner $F$ always exists' is true even though it doesn't 
"bear temporal relations" to us in the same sense as with the abstracta. The Platonist would agree with 'The number 7 always exists'; the presentist who believes in actual foreigners would agree with 'The foreigner $\mathrm{F}$ always exists'.

So I'm saying that foreigners are "omni-temporal" in the sense that abstracta are "omni-temporal".

A foreigner-friendly presentist is someone whose presentism is consistent with the metaphysical possibility of foreigners. She may strongly suspect or even believe that foreigners are metaphysically impossible, but if so she wants to bracket that modal claim when it comes to presentism. ${ }^{4} \mathrm{~A}$ xenophobic presentist is someone whose presentism is inconsistent with the metaphysical possibility of foreigners. The remainder of this section argues that the presentist should be foreigner-friendly because the overall evidence regarding foreigners is such that philosophers of time should not construct theories inconsistent with the metaphysical possibility of foreigners.

One might look to contemporary physics for evidence for foreigners. Some physicists say that time itself was created in the Big Bang; if they are right, and if we take a certain reading of 'create' and 'time', then perhaps there are other actual big bangs not spatiotemporally related to ours, and as a consequence there are foreigners. In addition, the "multiple universes" idea one encounters in discussions of the fine-tuning argument and elsewhere might be marshalled to promote the case for foreigners.

However, these empirical speculations are too weak to build a solid case for foreigners. The first speculation, regarding the creation of time and multiple big bangs is too weak since it relies on highly speculative assumptions. Furthermore, the Everettian solution to the measurement problem in quantum theory can be plausibly interpreted so that the other branches are temporally related to our branch (so they don't generate foreigners). ${ }^{5}$

Hence, although there is expert speculation that may lead to empirical if highly theoretical support for foreigners, right now the evidence from physics is weak. And if I'm wrong about that and it isn't weak, that makes the case for the thesis that the presentist should be foreigner-friendly just that much stronger.

What makes the (epistemic) possibility of foreigners interesting and relevant to presentism isn't the fact that the evidence for the metaphysical possibility of foreigners is strong but the fact that the evidence against it is so weak. We are left with no good reason to think there can't be foreigners. That's what I will argue for in the remainder of this section, looking at five alleged reasons for ruling out foreigners.

The first reason to be sceptical about the metaphysical possibility of foreigners comes from modal concerns. At first, foreigners look a bit like possibilia as conceived of by Lewis's Genuine M odal Realism, GMR [Lewis 1986]: entities that are as concretely existing just as much as we are but fail to bear any spatial or temporal relations to us. And yet, the comparison is poor because the thesis that foreigners are metaphysically possible does not entail or otherwise require just any possibilia not in

\footnotetext{
${ }^{4}$ Throughout this paper I assume the presentist wants her theory to be metaphysically necessary.

${ }^{5}$ Thanks to Jada Twedt Strabbing for insight on this point.
} 
our spatiotemporal region show up in the other actual spatiotemporal regions. This means that the problem with the thesis that foreigners are metaphysically possible is importantly different from the problem with mere possibilia that infects GM R. For one thing, the former thesis doesn't say that any foreigners are actual; it merely states that there could be universes with multiple disconnected maximal spatiotemporal regions. But the bolder thesis that there are actual foreigners is still crucially different from and avoids one of the primary defects of GM R. Although both GM R and 'There are foreigners' say that there are spatiotemporal entities just as concretely real as us but not temporally or spatially related to us, GM R says that anything possible has this status, whereas the thesis about foreigners says that only some things have that status-the actually existing foreigners. According to GM R, whether there are any talking donkeys not in our spatiotemporal region that are just as concretely real as our non-talking donkeys reduces to the question of whether such entities are even possible. This reduction strikes most philosophers as erroneous. According to the thesis of actual foreigners, however, whether there are any talking donkeys not in our maximal spatiotemporal region that are just as real as our non-talking donkeys has nothing at all to do with possibility (alone) and everything to do with how life has actually evolved on other planets (just not planets spatiotemporally related to us), which seems much less objectionable, at least by my metaphysical lights.

For those reasons, then, I don't think this modal objection to the metaphysical possibility of foreigners is any good. ${ }^{6}$ However, there is another modal objection.

Here we are in our spatiotemporal region, and we are considering two other metaphysically possible regions, $R_{h}$ and $R_{d}$, that aren't spatiotemporally related to our actual region. $R_{h}$ has talking horses; $R_{d}$ has talking donkeys. Suppose $R_{h}$ is actual (and thus foreign relative to us) while $R_{d}$ is not actual. This is the type of situation believers in foreigners think is metaphysically possible (and may be actual). What makes it the case that $R_{h}$ with its horses is actual while $R_{d}$ with its donkeys isn't? Neither one is related to us either temporally or spatially, so how do the talking horses deserve the title 'actual' while the talking donkeys do not? What makes $R_{h}$ actual if not some spatial or temporal relation to other actual entities including ourselves? What else is available to do that work?

Well, the horses exist and the donkeys don't (in the non-presentist sense of 'exist' used in metaphysics and recognized by presentists as logically complex). I don't know what's wrong with that unilluminating answer, but I'm not sure the question must have an illuminating one. Perhaps what entities are actual has nothing to do with mutual spatiotemporal relations. After all, that's exactly what Platonists think (the interesting difference being that abstract entities are presumed necessary whereas foreigners aren't).

Hence, I don't think the second modal consideration against foreigners is compelling.

A third reason to reject the metaphysical possibility of foreigners is as follows.

Mount Everest falls under E right now in virtue of being temporally present right now. And the number 7 falls under E right now in virtue of currently having a location in Plato's heaven. But foreigners are neither temporally present nor Platonically present, so to speak. As far as I can

\footnotetext{
${ }^{6}$ For additional relevant discussion in the context of GM R see Divers [2002: 6.2-6.4].
} 
see, there is no "in virtue of" truth that serves as the means for them to fall under E. So, they probably don't exist.

I think the presentist should accept everything up to the last sentence, the conclusion. Sure, foreigners don't fall under E in 2015 due to their being temporally present in 2015; neither are they abstract. So the two historically obvious ways of having positive ontological status don't apply to them. But so what? If we have learned anything at all from the history of physics and metaphysics, we have learned to keep an open mind regarding what might exist. So the presentist should not just assume there are only two ways for something to fall under E: be temporally present, and be abstract. As for a priori knowledge, perhaps ' $2+2=4$ ' is a priori, but 'The only way foreigners could fall under E is by being temporally present or in Plato's heaven' strikes me as a textbook case of overreaching. All we need to take foreigners seriously are a healthy scepticism for grand synthetic a priori reasoning and a genuine appreciation of the oddities of contemporary physics (these go together).

The fourth "reason", if you want to distinguish it with that title, against foreigners is that it's hard to imagine such entities. But I don't take mere failure of imagination to supply a good reason all by itself. Lewis [1986: 71-3] gives no reason to think they are impossible-other than the fact that his GMR works best (he says) with that impossibility. He also tries to account for the intuition for the metaphysical possibility of foreign entities by saying that other scenarios (that are consistent with the metaphysical impossibility of foreign entities) account for the plausibility of the intuition without suggesting its truth. But I'm not saying that there is any intuition for the metaphysical possibility of foreign entities. On the contrary, I think it is quite hard to vividly imagine foreign entities, as one is inevitably attracted to the idea that any actual temporal entity must be past, present, or future with respect to oneself. Even if one ends up rejecting that anti-foreigner idea one surely experiences its pull.

But as someone with a passing familiarity with the peculiarities of contemporary physics, such failures to vividly imagine a certain physical scenario no longer give me much reason to think the scenario is impossible (note that eternalists will agree here, as they draw great solace from Relativity theory, which challenges common sense). And I think it's a good rule of thumb to declare welldefined scenarios as possible unless one has a good argument to the contrary (so the default position is that a well-defined scenario is metaphysically possible), and I don't think Lewis (or Kant for that matter) gives us any such good argument.

My last argument that the presentist should take foreigners seriously is epistemic: the basic reasons we have for endorsing presentism give us no reason to think foreigners are metaphysically impossible or even non-actual, as follows.

The best evidence for presentism starts with ordinary empirical observation: one watches a paradigm case of something "going out of existence" and it seems as obvious as anything gets that this is an ontological change, in the sense articulated earlier: there is a crucial ontological difference between the bubble changing colour or shape and it's changing its temporal status from present to non-present. But could anything in that experience somehow justify the idea that there are no spatiotemporal regions not temporally related to ours? It seems outlandish to answer affirmatively. 
I suppose it goes without saying that presentism has been developed in such a way as to not take the possibility of foreigners into account. Even so, presentists have always had to make room for objects that are not part of our spatiotemporal region, such as abstracta. Presentists make this accommodation not necessarily because they are realists about such objects (although that's often the case). Rather, they do it because they don't want to unnecessarily tie presentism to the antirealist position. A nominalist presentist typically believes that her presentism would be true even if it turned out that there are abstracta. ${ }^{7}$ Presentists say that numbers, if they exist, exist at the present time even though they are not temporally present in the present time-where we precisify 'the present time' as referring to a physical entity, such as a hyperplane of our maximal spatiotemporal region of reality.

Presentists already recognize a common use of ' $x$ exists' such that it has the truth condition of ' $x$ is either abstract or temporally present, past, or future'; how she construes the logical form is a matter of debate that will continue and hopefully flourish as semantics gets more sophisticated (semantics is still in its infancy compared to other scientific disciplines, especially when it comes to temporal matters, where it is a new-born babe). I doubt that there will be anything stopping her from recognizing a more complicated use of 'x exists', so that it has the truth condition of ' $x$ is abstract, temporally present, or foreign'; again, matters of logical form will be have to be addressed.

Hence, if the above arguments are sound then we have no good reason to think foreigners are metaphysically impossible or even non-actual. Thus, we have no solid reason to accept that the common assumptions 'A temporal entity that is not temporally present $=$ a temporal entity that is in the past or future' and 'Every temporal entity is either past, present, or future' is metaphysically necessarily true, or even actually true (again, I'm setting aside details about the logical forms of theses like this one).

I have certainly not shown that the presentist must be foreigner-friendly. But I take it that the presentist who wishes to be xenophobic has to deliver the goods here: she needs to supply good arguments for the metaphysical impossibility of foreigners.

The next section addresses the foreigner-friendly presentist. The section after that addresses both her position as well as that of the xenophobic presentist.

\section{What Should Foreigner-Friendly Presentism Say about Foreigners?}

Which foreign entities fall under $E$ at a given time, according to the presentist who wants to accommodate foreigners?

It's natural to think the presentist should hold that at every time in our (maximal) spatiotemporal region all actual foreign entities fall under $E$. The alternatives are unattractive. It would make no sense to say that foreign entities fall under E only at specific times in our spatiotemporal region, since no specific time in our spatiotemporal region is appropriate for foreigners (as they bear no temporal relations to us). Neither would it make sense to distinguish among foreigners (saying that only some of them fall under $E$ at a given time in our region), since for us all of them are on a par (it

\footnotetext{
${ }^{7}$ In some sense of 'turned out'. Matters are difficult here in construing complex conditionals with antecedents that may, epistemically, have metaphysically impossible antecedents.
} 
makes no sense for us to ask 'W hich foreign entities are temporally present right now?' because the 'right now' refers to a time in our region but not their region).

In addition, there is precedent for my claim that all foreigners fall under $E$ at all times: the presentist who is a realist about abstracta already admits that all abstracta fall under $E$ at every time even though they aren't part of our spatiotemporal world; analogously, she should, if she is friendly to foreigners, say that all actual foreigners fall under $E$ at every time even though they aren't part of our spatiotemporal world. Intuitively, the metaphysically relevant distinction between present and non-present entities, captured with $\mathrm{E}$, certainly looks to be the sole central ontological distinction (all others are derivative); so, if abstracta exist in any sense at all then they must fall under $E$. $E$ is necessarily limited to temporally present entities only if it's S5-necessary (i.e., in all possible worlds, accessible or not) that there are no foreigners or abstracta. A presentist will insist that $E$ isn't restricted to temporally present entities, provided she believes in abstract or foreign entities.

For those reasons then, the foreigner-friendly presentist should reject the idea that what falls under $E$ at a given time is limited to present and abstract entities. Instead, her position should be that what falls under $\mathrm{E}$ at a certain time are all present, abstract, and (actual) spatiotemporally foreign entities. Again, this is not to say that she should believe in foreign entities-any more than she should believe in abstract ones-but that her thesis should allow for the possibility.

Foreigners don't only require the presentist to shift her position: a similar point holds for foreignerfriendly eternalists. As alluded to above, eternalists think that at any given time all present, past, future, and abstract objects fall under $E$ (so its extension never changes). I'm suggesting that they should say that at any given time what falls under E may include entities that are not past, present, future, or abstract-but the extension will not vary over time, so that feature of eternalism won't change.

\section{The New Objections to Foreigner-Friendly Presentism}

Accommodating the possibility of temporal foreigners sounds philosophically open-minded, in the best sense of the term. But it leads to three new objections to foreigner-friendly presentism. I will articulate them and offer only a few brief remarks on how the presentist might go about beginning to formulate responses.

Here is the first objection.

You want to say that at any given moment in our spatiotemporal region all foreign entities fall under $E$, along with all temporally present and abstract entities. Now consider a person in one of the foreign regions. According to your proposal, she will, at any given time, say that all temporally present (to her) entities, all abstract entities, and all foreign entities fall under E. But that means that the two of you disagree on what exists. You say that all the entities in her region fall under Enow; she says that only some of them do (the ones temporally present with respect to her). Thus, $\mathrm{E}$ is not objective at all: people in different regions never agree on what falls under

E. That contradicts the definition of $E$ since it is supposed to be absolute.

In order to think about how the presentist should respond, consider first two people in our region but at different times. According to the presentist they of course will give different yet true answers regarding what falls under E: a person in 1950 would correctly say that Edmund Husserl currently 
falls under E whereas we in 2015 would not. But the difference is entirely expected given that the circumstances of evaluation have changed in an appropriate manner according to the presentist: the time at which we judge what falls under E affects the true answer. The pair of differing true answers is just an uninteresting consequence of indexicality.

Now consider the foreigner judging what falls under $E$ at one of her times. The presentist should say that there is no reason to think that her answer should match ours-for the just about the same reason that there is no reason to think that the 1950s person's answer should match ours. The respective answers depend on the times of evaluation, and it's impossible to take her answer and evaluate it with regard to any of our times (and it's impossible to take our answer and evaluate it with regard to any of her times).

This may be an adequate solution to the objection, but it means that the foreigner-friendly presentist has to hold that we cannot take a fully universal view and try to say what really, truly falls under $\mathrm{E}$ for the whole actual universe at a given time- because there might not be any such thing as "the" time for the whole actual universe even when we ignore General Relativity. (The 'might' is crucial, as the presentist need not be affirming the metaphysical possibility of foreigners; she is merely making room for them.) Eternalists usually say that there is no such thing as "the" time for the whole actual universe as a result of their typical endorsement of contemporary physical theory. Now we see that foreigner-friendly presentists must do this as well-the difference being that eternalists typically reject while presentists typically accept that there is a single time for a particular maximal spatiotemporal region. If there are conceptually possible non-empty fully atemporal worlds - so nothing but abstract objects in them-then perhaps $E$ can be evaluated at those worlds without a time reference, and thus can provide a fully transcendent view, but for any world with foreigners that won't be the case.

The second objection to foreigner-friendly presentism is harder to answer.

According to someone in a region foreign with respect to us, all the entities in our past, present, and future simultaneously fall under $E$ at any of her times. Well, that means that there is an ontological notion-E, the one we care about!-that all our past, present, and future entities fall under at the very same time. Well, if that's true, then how can we say that they do not all fall under $\mathrm{E}$ at the very same time? Haven't we just said that there is a time-a foreign one-at which all our past, present, and future entities fall under E? How can that be consistent with presentism?

In response, perhaps the presentist will have to admit that there are ontological distinctions that we know about but can't express for some reason. Take two flowers from some foreign region that do not overlap in the time of their region. We know that there are times in that region according to which one flower falls under $E$ while the other does not, but all we, in our region, can say is that both flowers fall under $E$ at every time in our region. It's almost as though the presentist needs to find an ontological notion tied not to any of her "local" times but to a truly universal time or other temporal notion; and then she needs to offer a new kind of presentism that uses that universal temporal notion. Good luck with that.

The third objection to foreigner-friendly presentism is more of a challenge than an attempted refutation. 
You are now admitting that some entities that fall under E right now, the foreigners, are not temporally present even though they are ordinary temporal entities. Well, if you're going to let them in even though they aren't temporally present, then how can you justify not letting past or future entities in as well? After all, you just admitted that being temporally absent is no obstacle for a temporal entity to fall under E! Since you have repudiated your xenophobic ways, you are now saying that there is an ontological distinction between two temporally absent flowers: one foreign and the other domestic but past. But how can you refuse admittance to the domestic flower just because she isn't temporally present, given that the foreign one isn't temporally present either?

I don't know how the presentist should respond other than simply going xenophobic. But this strikes me as an instance of an awful methodology: you come up with a plausible view; someone points out that such-and-such entities may well exist; you realize that you really don't have much reason to assert that those entities are metaphysically impossible; but then it's pointed out that if they are metaphysically possible, then your view suffers some horrible pain; so in response you assert that the entities are metaphysically impossible-and you do this solely because it would cause difficulties with your theory. If the evidence for presentism was overwhelming, then this might be a reasonable cognitive move, but I doubt the antecedent.

In any case, the presentist needs to take a stand on foreigners and then justify it: the foreignerfriendly one has to respond to these three objections, and the xenophobic one has to justify her assertion that foreigners are metaphysically impossible.

\section{References}

Crisp, Thomas 2003. Presentism, in Oxford Handbook of M etaphysics, ed. Michael Loux and Dean Zimmerman, New York: Oxford University Press: 211-245.

Crisp, Thomas 2004. On Presentism and Triviality, in Oxford Studies in M etaphysics, vol. 1, ed. Dean Zimmerman, New York: Oxford University Press: 15-20.

Divers, John 2002. Possible Worlds, London: Routledge.

Lewis, David 1986. On the Plurality of Worlds, Malden, M A: Blackwell.

Markosian, Ned 2004. A Defense of Presentism, in Oxford Studies in M etaphysics, vol. 1, ed. Dean Zimmerman, New York: Oxford University Press: 47-82.

Sider, Theodore 2006. Quantifiers and Temporal Ontology, Mind 115/457: 75-97. 